\title{
O Atlas do Câncer
}

The Cancer Atlas

El Atlas del Cáncer

\author{
Jemal A, Vineis P, Bray F, Torre L, Forman D (Eds). O atlas do câncer. 2.ed. Atlanta, GA: \\ American Cancer Society; 2014. \\ ISBN: 978-1-60443-228-2 (impresso).
}

\author{
Giovani Miguez'1
}

O Atlas do Câncer é uma publicação, de acesso livre, da American Cancer Society (Sociedade Americana de Câncer - ACS), editada em parceria com a Uniáo Internacional para Controle do Câncer (UICC) e desenvolvida com o objetivo de aprimorar as consultas de assuntos sobre o Câncer em um cenário mundial e traçar um panorama global da doença por meio de informaçôes coletadas em 185 países. No Brasil, a tradução da sua segunda edição foi realizada pelo Hospital de Câncer de Barretos.

O Atlas consolida informaçôes objetivas e impactantes em uma linguagem de fácil acesso que, além de dar elementos para uma melhor compreensão do impacto do câncer na sociedade em diversos cenários pelo mundo, incluindo a América Latina, merece atenção de estudantes e profissionais de saúde envolvidos na problemática do câncer. Nesse sentido, funciona como uma ferramenta importante para a disseminação de informaçôes e dados sobre as reais dimensôes de uma doença que, não obstante atingir todo o mundo, ainda carece de compreensão por grande parte da sociedade e, inclusive, dos profissionais de saúde não envolvidos diretamente na temática do câncer.

A publicação reúne opiniōes de 40 especialistas - entre autores e pareceristas - de diversos países, com atuação profissional diversificada, seja em instituições acadêmicas e governamentais, além de organizações não governamentais.

O Atlas fornece informaçóes que vão além da carga global do câncer que, stricto sensu, é uma métrica de anos de vida perdida por morte ou incapacidade. Seu formato acessível, de fácil acesso e uso, transforma a publicação em um instrumento útil também para diversos atores sociais e políticos envolvidos da defesa de usuários dos sistemas de saúde, para agências de saúde pública, diversas organizaçôes privadas e públicas, além de legisladores envolvidos nas açôes de controle do câncer e jornalistas e profissionais de comunicação dispostos a se apropriarem de informaçóes em uma perspectiva global sobre promoção, prevenção e controle do câncer.

Em termos de estrutura editorial, o Atlas procurou manter a estrutura da primeira edição (2006), ampliando, entretanto, na segunda, a abrangência das informações. Contemplou-se, desse modo, um panorama global das informações sobre a carga do câncer, os fatores de risco associados, os métodos de prevenção e as medidas de controle.

Na primeira seção, é destacada a magnitude das variaçóes regionais e internacionais entre os diversos fatores de risco do câncer. Ao longo de oito capítulos, são contempladas informaçóes sobre poluentes ambientais, alimentação não saudável e obesidade, carcinógenos ocupacionais, infecçôes, radiações e hábitos reprodutivos. Destacam-se o tabagismo, por ainda ser a causa predominante de câncer na maioria dos países de alta renda, as infecçôes pelo papel de destaque em muitos países da África Subsaariana e da Ásia, e, por fim, a obesidade pela sua relevância crescente como um fator de risco maior para o câncer em muitas partes do mundo, inclusive nos países de média e baixa rendas.

$\mathrm{Na}$ segunda seção, ampliada de forma substancial desde a primeira edição, ao longo de 13 capítulos, a carga do câncer é tratada em todas as principais regióes do globo. Os dados demonstram uma impressionante diversidade geográfica no padráo de diferentes cânceres, com destaque para pulmão, mama e câncer infantil.

${ }^{1}$ Gestor Público com Extensão em Jornalismo de Políticas Públicas. Especialista em Sociologia. Mestre em Ciência da Informação e Analista de Ciência e Tecnologia do Instituto Nacional de Câncer José Alencar Gomes da Silva (INCA).E-mail: gsilva@inca.gov.br. 
Segundo a Organização Mundial da Saúde (OMS), a carga de doenças é uma medida baseada no tempo que combina anos de vida perdidos devido à mortalidade prematura e anos de vida perdidos devido ao tempo vivido em estados de plena saúde. A métrica DALY, utilizada pela OMS, é utilizada para avaliar o impacto da doença de forma consistente em determinadas doenças, fatores de risco e regiôes. No Atlas, a descrição da carga, segundo o os autores, é feita de acordo com o "Índice de Desenvolvimento Humano e em termos de anos de vida perdidos (YLL), uma medida que dá mais peso às mortes que ocorrem em pessoas mais jovens".

A terceira seção, distribuída em 14 capítulos, trata das medidas adotadas e faz uma rica descrição dos principais tipos de "intervenção no espectro do câncer, da prevenção dos fatores de risco à detecção precoce, o tratamento e os cuidados paliativos". Dedica, ainda, significativa atenção às disparidades na aplicação dessas intervenções em âmbito mundial. Outra informação que merece destaque é o espaço dedicado a descrever as principais organizaçóes que trabalham no controle do câncer, as políticas e a legislaçáo recentes para enfrentar o problema do câncer.

O Atlas ainda contém um apêndice que, além de fartas tabelas com o panorama mundial e um glossário com termos eventualmente desconhecidos para não especialistas em saúde, possui uma interessante cronologia sobre a história do câncer que remonta os primórdios da existência de vida no planeta, com evidência de células cancerígenas em fósseis de dinossauros, descobertos em 2003, até as conquistas recentes, como, por exemplo, a entrada em vigor, em 2005, da Convenção-Quadro para o Controle do Tabaco da OMS, usando o direito internacional para promover saúde pública e prevenir o câncer.

Considerando o câncer como um problema mundial e levando-se em conta o crescimento e o envelhecimento da população, o Atlas nos apresenta uma estimativa de que o número de novos casos de câncer aumente de mais de 14 milhôes em 2012 para cerca de 22 milhôes em 2030 em todo o mundo. O maior crescimento, da ordem de 70\%, será visto na África, Ásia e América Latina. Desse modo, o acesso a informaçóes detalhadas e dispostas em tabelas, ilustraçôes e gráficos são extremamente relevantes para que o problema possa ser enxergado por toda a sociedade em toda sua magnitude e em âmbito mundial.

A versão em português do Atlas do Câncer pode ser acessada no seguinte endereço eletrônico: www.atlasdocancer. com.br. 